\title{
AGROINDUSTRI KAKAO UNTUK MENINGKATKAN PENDAPATAN MASYARAKAT PETANI DI KABUPATEN KONAWE
}

\section{COCOA AGRO-INDUSTRY TO INCREASE FARMERS REVENUE IN KONAWE DISTRICT}

\author{
Rayuddin \\ Dosen Program Studi Agribisnis Fakultas Agroindustri dan Pertanian Universitas Lakidende \\ Email : raybilqis@gmail.com
}

\begin{abstract}
The aim of cocoa agro-industry innovation is to apply the cocoa bean fermentation technique by using a fermentation box specifically designed to improve the quality of cocoa beans in the community cocoa farms, so that they have a higher selling value and can increase the income of cocoa farmers. The economic value of people's cocoa products is still dominantly obtained from primary products causing the acquisition of income per unit of cocoa farming product units is relatively low. The added value of cocoa can be obtained by the community by fermenting cocoa beans in the post-harvest cocoa process. The problem is how to improve the quality of cocoa beans in the post-harvest process into fermented cocoa beans that have a higher selling value so as to increase the income of cocoa farmers. The cocoa fermentation technique is done by: (a) wet cocoa beans put into a fermentation box size $30 \times 30 \times 30 \mathrm{~cm}$ (p.l.t) for 48-27 hours, (b) cocoa beans reversal and stirring, (c) controlling the temperature of cocoa beans at least 52 degrees Celcius, $(d)$ washing cocoa beans, (e) drying cocoa beans, and $(f)$ storing and packaging cocoa beans. The results showed that the value of fermented cocoa bean products could increase the selling price of quality fermented cocoa (52.17 percent) and increase the value of people's cocoa farm income by IDR. 23,268,000.00 .- ha $a^{-1}$ year in plantation communities.
\end{abstract}

Keywords: Cocoa Agro-Industry, Fermentation, Income, Plantation Community

\begin{abstract}
ABSTRAK
Tujuan inovasi agroindustri kakao adalah menerapkan teknik fermentasi biji kakao dengan menggunakan kotak fermentasi yang didesain khusus guna meningkatkan kualitas biji kakao pada usahatani kakao rakyat, sehingga memiliki nilai jual yang lebih tinggi dan dapat meningkatkan pendapatan petani kakao. Nilai ekonomi produk kakao rakyat masih dominan diperoleh dari produk primer menyebabkan perolehan pendapatan per satuan unit produk usahatani kakao tergolong relatif rendah. Nilai tambah komoditas kakao dapat diperoleh masyarakat dengan cara melakukan fermentasi biji kakao dalam proses pasca panen kakao. Masalahnya adalah bagaimana meningkatkan kualitas biji kakao dalam proses pascapanen menjadi produk biji kakao fermentasi yang mempunyai nilai jual yang lebih tinggi sehingga dapat meningkatkan pendapatan petani kakao. Teknik fermentasi kakao dilakukan dengan cara: (a) biji kakao basah dimasukkan kedalam kotak fermentasi ukuran 30x30x30 cm (p.l.t) selama 48-27 jam, (b) pembalikan dan pengadukan biji kakao, (c) pengontrolan suhu biji kakao minimal 52 derajat celsius, (d) pencucian biji kakao, (e) pengeringan biji kakao, serta (f) penyimpanan dan pengemasan biji kakao. Hasil penelitian menunjukkan bahwa nilai produk biji kakao fermentasi dapat meningkatkan harga jual kakao kualitas fermentasi (52,17 persen) dan meningkatkan nilai pendapatan usahatani kakao rakyat sebesar Rp 23.268.000,00.-/ha per tahun dalam masyarakat perkebunan.
\end{abstract}

Kata Kunci : Agroindustri Kakao, Fermentasi, Pendapatan, Masyarakat Perkebunan 


\section{PENDAHULUAN}

Tanaman kakao (theobroma cocoa L) adalah salah satu komoditas andalan perkebunan yang peranannya sangat penting sebagai sumber mata pencaharian penduduk dan perekonomian daerah Konawe, disamping juga sebagai penyedia lapangan kerja, sumber pendapatan dan penghasilan devisa negara. Namun demikian, potensi produksi kakao rakyat masih dibawah rata-rata produksi kakao nasional yakni sebesar 1,2 ton/ha (BPS, 2010). Hal tersebut disebabkan karena pelaku usahatani kakao relatif masih rendah menerapkan sistem agribisnis/agroindustri secara utuh dalam pengelolaan usahatani kakao, terutama pada sub sistem prosesing dan pengolahan hasil kakao (off-farm) yang mampu memberikan nilai tambah (value added) serta daya saing mutu kakao di pasaran dunia.

Usaha pengolahan hasil perkebunan kakao berupa pengolahan biji kakao sejak lama telah dilakukan petani, akan tetapi belum memberikan hasil seperti yang diharapkan. Terkait dengan ketahanan pangan menjadi hal yang memperihatinkan bahwa ada banyak produk olahan makanan secara lokal dan spesifik sudah semakin jarang ditemui di kalangan masyarakat pedesaan. Kalau kita mendatangi suatu desa sentra pertanian, secara visual akan terlihat adanya gejolak peningkatan mengkonsumsi makanan yang cenderung kearah serba instant. Fenomena seperti ini terjadi karena adanya isu pengembangan agroindustri kakao untuk meningkatkan pendapatan masyarakat petani yang telah dicanangkan sejak dua puluh tahun lalu, tampaknya sampai saat ini belum direalisasikan dengan benar sebagai basis kegiatan ekonomi rakyat di pedesaan.

Masalahnya adalah bagaimana meningkatkan kualitas biji kakao dalam proses pascapanen dari kualitas asalan (tidak difermentasi) menjadi kakao fermentasi yang mempunyai nilai jual yang lebih tinggi sehingga dapat meningkatkan pendapatan petani kakao. Gambaran fluktuasi harga kakao di tingkat petani bervariasi saat panen kakao yakni berada pada kisaran harga Rp 11.000,00 hingga $\mathrm{Rp} 23.000,00$ per $\mathrm{kg}$ dan sangat ditentukan oleh tingkat kekeringan biji kakao dan perlakuan fermentasi. Perilaku petani kakao masih sering menjual kakao basah yang nilainya seharga $\mathrm{Rp} 7.000,00$ per kg kakao basah. Kondisi ini terjadi karena petani kakao belum banyak yang melakukan proses pascapanen kakao dengan baik (fermentasi) saat panen kakao sehingga mutu biji kakao yang dihasilkan masih asalan (non fermentasi) dan berpengaruh pada nilai jual kakao dipasaran konsumen. Salah satu inovasi yang ditawarkan adalah penggunaan kotak fermentasi yang didesain khusus dalam menerapkan teknik fermentasi biji kakao untuk memperbaiki mutu kakao dan kualitas produksi usahatani kakao rakyat dalam proses pascapanen kakao (Rayuddin, 2010).

Saat ini cokelat (kakao) merupakan kategori camilan terfavorit urutan ke-empat setelah kategori pastray, biskuit, dan permen dengan nilai pasar hingga 776 juta USD atau sekitar Rp 11,2 triliun rupiah. Menjanjikannya peluang industri kakao di Indonesia yang masih berkisar 78 persen, karena potensi pada industri kakao masih ditentukan dengan rendahnya tingkat konsumsi kakao di Indonesia yakni masih sekitar $0,5 \mathrm{~kg}$ per orang per tahun. Cocoa Life Director for Southeas Asia (Mondelez International,2018) menyatakan bahwa meskipun Indonesia merupakan negara penghasil kakao terbesar ketiga di dunia, namun perkebunan kakao masih menghadapi berbagai tantangan diantaranya karena perkebunan kakao masih 
dilakukan secara tradisional, sehingga produktivitasnya rendah dan ketertarikan petani untuk membudidayakan kakao juga rendah. Mondelez Internasional sebagai salah satu agroindustri kakao terbesar di dunia, tetap berkomitmen memberikan solusi dalam menjaga keberlanjutan kakao melalui program Cocoa Life. (https://www.tribunnews.com >Mondelez International, konsumsi cokelat di Indonesia, diakses tanggal 2 Agustus 2018).

Teknologi pengolahan hasil kakao yang sudah ada terdahulu adalah fermentasi biji kakao dalam karung, menggunakan peti dan fermentasi biji kakao diatas terpal plastik yang ditutupi dengan daun-daunan terutama daun pisang. Petani menerapkan cara fermentasi tersebut, dengan maksud untuk menyimpan produk usahataninya agar praktis dapat dikeringkan. Kelemahan teknologi yang terdahulu adalah belum ada desain pembuatan kotak fermentasi secara khusus sesuai kebutuhan kapasitas biji kakao dalam setiap periode panen. Disamping itu, tahapan proses fermentasi biji kakao secara sempurna untuk mematikan inti biji dan pelepasan lendir biji kakao sebagai zat pembentuk aroma tidak dipertimbangkan dalam proses fermentasi biji kakao.

Tujuan inovasi agroindustri kakao adalah mengatasi masalah teknis dan kelemahan teknologi yang sudah ada terdahulu, untuk menerapkan teknik fermentasi biji kakao dengan menggunakan kotak fermentasi yang didesain khusus guna meningkat kualitas biji kakao pada usahatani kakao rakyat sehingga memiliki nilai jual yang lebih tinggi dan dapat meningkatkan pendapatan petani kakao melalui proses fermentasi biji kakao secara sempurna. Secara teknis biji kakao yang melalui proses fermentasi akan memberikan perubahan terhadap pembentukan cita rasa kakao, pengurangan rasa pahit dan sepat, serta perbaikan penampakan fisik biji kakao.

\section{METODE PENELITIAN}

Kajian inovasi agroindustri kakao untuk meningkatkan pendapatan masyarakat perkebunan (petani kakao) di Kabupaten Konawe, merupakan implementasi konsep "working with community" sebagai bentuk metode pembelajaran teknik fermentasi biji kakao bagi masyarakat perkebunan. Obyek penelitian adalah petani kakao berjumlah sebanyak 180 orang dan luas areal lahan usahatani kakao seluas 235 hektar, dengan tingkat produktivitas usahatani kakao rata-rata $700 \mathrm{~kg}$ per hektar. Nilai pendapatan usahatani kakao rata-rata sebesar Rp 19.000.000,- /ha per tahun. Lokasi penelitian di fokuskan pada wilayah sentra produksi kakao Kabupaten Konawe, Provinsi Sulawesi Tenggara.

Inovasi teknologi agroindustri berupa teknik fermentasi biji kakao dapat diuraikan dengan langkah kerja sebagai berikut:

\section{Langkah Persiapan Fermentasi}

a. Membuat kotak fermentasi dengan ukuran $30 \times 30 \times 30 \mathrm{~cm}$ (P x L x T).

b. Buah kakao hasil panen dibelah dengan menggunakan alat yang terbuat dari kayu, karena jika menggunakan parang atau benda tajam terbuat dari besi lainnya kemungkinan akan ada biji yang pecah dan berakibat terhadap kontaminasi biji yang akan difermentasi.

c. Pisahkan biji-biji kakao yang utuh dari biji-biji yang terserang penggerek buah kakao (PBK) ataupun biji-biji yang tercampur dengan benda lain.

\section{Langkah Pelaksanaan Proses Fermentasi}

a. Hari pertama (Penimbangan awal, selanjutnya memasukkan biji kakao kedalam kotak fermentasi)

Hal yang perlu diperhatikan : Kotak fermentasi harus bersih dan pastikan lubang-lubang kotak tidak tersumbat; Melakukan penimbangan awal; Perlu 
dilakukan penutupan dengan menggunakan daun pisang.

b. Hari kedua (Pembalikan dengan memindahkan biji kakao ke kotak lain)

Hal yang perlu diperhatikan : Alat aduk yang digunakan terbuat dari kayu; Upayakan saat pembalikan harus pada 48 jam dari waktu pemasukan biji ke kotak; Pembalikan dimulai dari atas kebawah dengan memindahkannya ke kotak lain; Penutupan kembali.

c. Hari ketiga (Pengontrolan dan pengecekan proses)

Hal yang perlu diperhatikan : Pengelupasan kulit luar (akan nampak berwarna coklat); Aroma biji kakao yang difermentasi seperti bau asam cuka, jika tercium bau tengik berarti segera dilakukan penjemuran.

d. Hari keempat (Pengecekan, penimbangan berat akhir,serta persiapan pengeringan)

Hal yang perlu diperhatikan : Pengelupasan kulit luar (Nampak sekali warna coklat); Bila dipencet akan keluar cairan coklat; Aroma biji kakao yang difermentasi seperti bau asam cuka, jika tercium bau tengik berarti segera dilakukan penjemuran; Penimbangan berat akhir.

\section{Langkah Pengeringan Biji Kakao}

a. Pengeringan dapat dilakukan dengan penjemuran alami (sinar matahari);

b. Pengeringan dengan menggunakan alat pengering (dryer);

c. Pengeringan dengan kombinasi keduanya (a dan b)

Cara yang perlu dilakukan untuk mengetahui selesainya pengeringan bijikakao: Berdasarkan penurunan berat biji yaitu apabila berat biji kering telah mencapai $1 / 3$ dari berat basah atau kadar air 5 - 7 persen (kering patah); Biji kakao yang sudah kering biasanya rapuh dan mudah patah; Bila di genggam kemudian di lepas semua biji akan jatuh (tidak melengket di tangan).

\section{Langkah Penyimpanan Biji kakao}

Hal penting yang harus diperhatikan selama penyimpanan biji kakao kering : Karung tidak boleh diletakkan diatas lantai semen karena biji kakao kering dapat menyerap air dari lantai; Jangan masukkan biji kakao kering yang masih panas ke dalam karung,biarkan biji kakao dingin terlebih dahulu; Tempat penyimpanan biji kakao harus bebas dari terpaan langsung air hujan dan hama perusak biji kakao. Skema proses fermentasi biji kakao, dapat disajikan pada gambar 1 berikut ini.

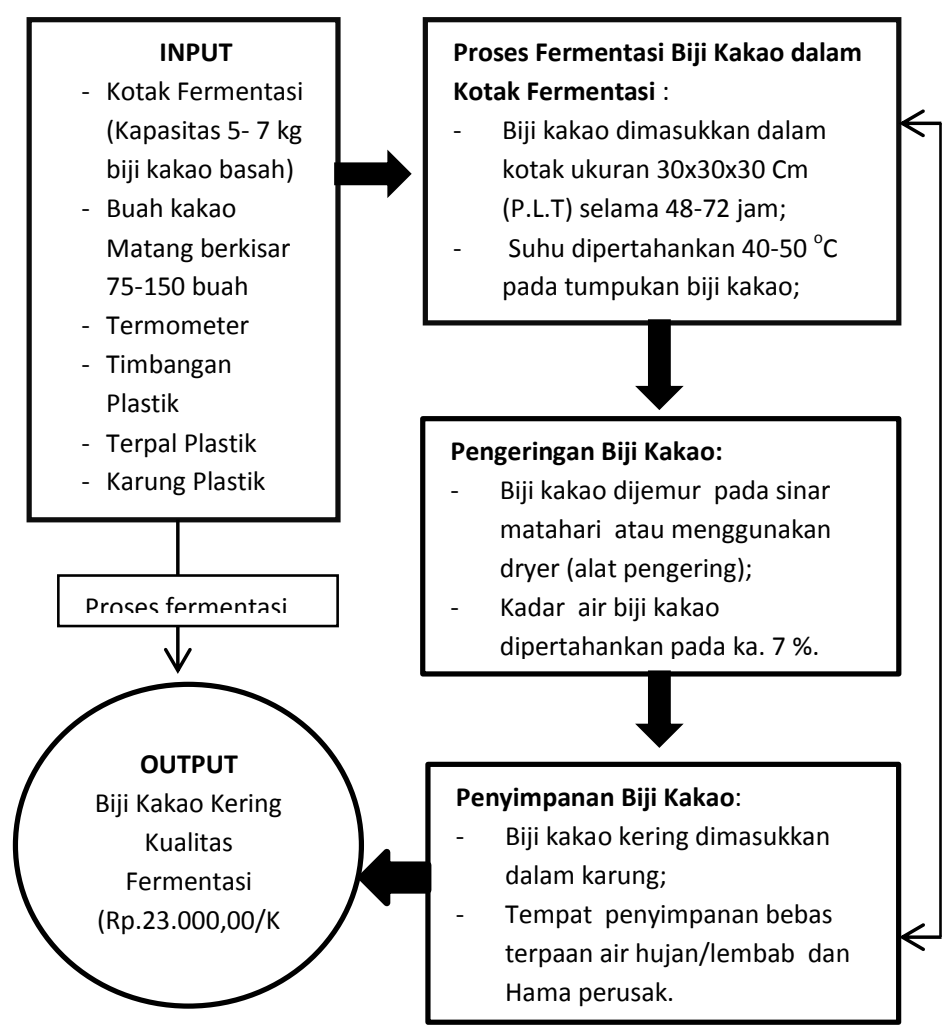

Gambar 1. Skema Proses Fermentasi Biji Kakao

HASIL DAN PEMBAHASAN

1. PRODUKTIVITAS USAHATANI

KAKAO RAKYAT

Produktivitas merupakan representasi kombinasi semua faktor produksi, dan ini dipengaruhi oleh tingkat kompetensi dan 
motivasi kerja. Pada hakekatnya esensi dari peningkatan produktivitas adalah bekerja dengan lebih cerdik, bukan bekerja dengan lebih keras. Beberapa hasil penelitian menunjukkan peningkatan produktivitas kerja dibatasi oleh kemampuan kerja seseorang sehingga perlu melakukan kerja dengan cerdik. Tingkat produktivitas usahatani kakao rakyat di daerah penelitian dapat disajikan pada Tabel 1, berikut ini.

Tabel 1. Sebaran Petani Responden Berdasarkan Tingkat Produktivitas Usaha Tani Kakao Rakyat Di Wilayah Penelitian

\begin{tabular}{lccc}
\hline $\begin{array}{l}\text { Kategori } \\
\begin{array}{l}\text { Produktivitas } \\
\text { usahatani }\end{array}\end{array}$ & $\begin{array}{c}\text { Tingkat } \\
\text { Produktivitas } \\
(\mathrm{kg} / \mathrm{ha})\end{array}$ & $\begin{array}{c}\text { Petani } \\
\text { Responden } \\
(\mathrm{n})\end{array}$ & $\begin{array}{c}\text { Persentase } \\
(\%)\end{array}$ \\
\hline Sangat rendah & $\leq 400$ & 63 & 35.0 \\
Rendah & $>400-800$ & 68 & 37.8 \\
Sedang & $>800-1200$ & 49 & 27.2 \\
Tinggi & $>1200-1600$ & 0 & 0.0 \\
Sangat tinggi & $>1600$ & 0 & 0.0 \\
\hline Jumlah & & 180 & 100.0
\end{tabular}

Pada Tabel 1, menunjukkan bahwa dominan produktivitas usahatani kakao rakyat yang dicapai dalam kebun petani persatuan areal masih terkategori rendah $\quad(37,8 \%)$, hal tersebut banyak disebabkan oleh kurangnya perhatian petani dalam hal pemeliharaan tanaman yang mencakup: kegiatan pemupukan, pengendalian hama-penyakit tanaman kakao, dan pembersihan kebun dari gulma. Perhatian terhadap teknik budidaya dan pemeliharan tanaman kakao, dan juga sangat berkaitan dengan mutu dan kualitas hasil usahatani kakao yang ditingkat petani.

\section{PENERAPAN TEKNIK FERMENTASI BIJI KAKAO \\ RAKYAT}

Pengolahan hasil usahatani kakao rakyat, dilakukan setelah kegiatan produksi. Pengetahuan dan keterampilan yang dibutuhkan dalam melakukan kegiatan pengolahan hasil kakao, meliputi; pengolahan biji kakao melalui proses fermentasi, pengeringan, sortasi, dan penyimpanan. Perlakuan fermentasi biji kakao rakyat di wilayah penelitian dapat disajikan pada Tabel 2 , berikut ini.

Tabel 2. Sebaran Petani Responden Berdasarkan Perlakuan Fermentasi Biji Kakao Di Wilayah Penelitian

\begin{tabular}{|c|c|c|c|}
\hline $\begin{array}{l}\text { Perlakuan } \\
\text { Proses } \\
\text { Fermentasi } \\
\text { Biji Kakao }\end{array}$ & $\begin{array}{c}\text { Bobot Biji Kakao } \\
\text { Basah (kg) }\end{array}$ & $\begin{array}{c}\text { Petani } \\
\text { Responden } \\
\text { (n) }\end{array}$ & $\begin{array}{c}\text { Persentase } \\
\quad(\%)\end{array}$ \\
\hline $\begin{array}{l}\text { Sangat } \\
\text { rendah }\end{array}$ & $\leq 100$ & 0 & 0.0 \\
\hline Rendah & $>100-200$ & 94 & 52.2 \\
\hline Sedang & $>200-300$ & 56 & 31.1 \\
\hline Tinggi & $>300-400$ & 23 & 12.8 \\
\hline Sangat tinggi & $>400$ & 7 & 3.9 \\
\hline Jumlah & & 180 & 100.0 \\
\hline
\end{tabular}

Pada Tabel 2, menunjukkan bahwa perlakuan proses fermentasi biji kakao dominan terkategori masih rendah (52.2\%) yang dilakukan oleh petani kakao. Perhatian petani untuk melakukan proses fermentasi biji kakao dalam pengolahan biji kakao bermutu masih rendah, banyak disebabkan oleh tingkat pengetahuan dan kemampuan petani kakao yang rendah, disamping waktu yang dibutuhkan untuk melakukan fermentasi biji kakao, karena umumnya petani kakao ingin segera menjual hasil usahataninya agar memperoleh uang cash dari pembeli/pedagang kakao secara cepat untuk memenuhi kebutuhan hidup keluarganya.

\section{ANALISIS PENDAPATAN USAHATANI KAKAO RAKYAT}

Tingkat pendapatan petani kakao sangat ditentukan dari besar- kecilnya hasil panen buah kakao yang diperoleh dalam setahun, sehingga perhitungan pendapatan rata-rata bulan/minggu/hari hanya dapat ditentukan dari hasil bagi satuan pendapatan per tahun. 
Menurut Soekartawi (2010) bahwa nilai pendapatan usahatani diperoleh dari total penerimaan dikurangi dengan total biaya dalam suatu siklus produksi usahatani kakao, dan secara matematis rumus pendapatan (I= TR- TC), dimana Income atau pendapatan merupakan selisih antara Total Review atau total penerimaan dengan Total Cost atau total biaya. Pendapatan petani kakao yang melakukan fermentasi biji kakao, dibandingkan dengan pendapatan petani kakao yang tidak melakukan fermentasi biji kakao, dapat diuraikan berikut ini.

a. Nilai Pendapatan Produk Fermentasi Biji Kakao

Nilai pendapatan usahatani kakao rakyat yang melakukan fermentasi biji kakao, setelah dihitung penerimaan dan biaya yang dikeluarkan dengan satuan produksi dan satuan harga yang berlaku sebagaimana pada Tabel 3.

Tabel 3. Nilai Pendapatan Usahatani Setiap $100 \mathrm{Kg}$ Biji Kakao Hasil Fermentasi Di Wilayah Penelitian

\begin{tabular}{clll}
\hline No & \multicolumn{1}{c}{$\begin{array}{c}\text { Variabel } \\
\text { Pendapatan }\end{array}$} & $\begin{array}{l}\text { Volume } \\
\text { Satuan } \\
(\mathrm{Rp} / \mathrm{kg})\end{array}$ & $\begin{array}{c}\text { Total Nilai } \\
(\mathrm{Rp})\end{array}$ \\
\hline 1 & $\begin{array}{l}\text { Penerimaan biji } \\
\text { kakao fermentasi }\end{array}$ & 100 & $2.300 .000,00 .-$ \\
2 & Biaya - biaya & 100 & $700.000,00 .-$ \\
3 & Harga biji kakao/kg & $23.000,00 .-$ & $23.000,00 .-$ \\
\hline & Nilai Pendapatan & & $\mathbf{1 . 6 0 0 . 0 0 0 , 0 0 . -}$ \\
& $(1-2)$ & & \\
\hline
\end{tabular}

Pada Tabel 3, menunjukkan bahwa nilai pendapatan usahatani kakao dengan produk fermentasi biji kakao adalah sejumlah $\mathrm{Rp}$ 1.600.000,00.- per setiap $100 \mathrm{~kg}$ biji kakao fermentasi. Hal tersebut berlaku pada tingkat harga jual biji kakao standar fermentasi sebesar Rp 23.000,- per kg, dan standar harga biji kakao basah sebesar Rp 7.000,- per kg di tingkat pedagang pengumpul kakao. b. Nilai Pendapatan Produk Asalan Biji Kakao (non fermentasi)

Nilai pendapatan usahatani kakao rakyat yang tidak melakukan fermentasi biji kakao, setelah dihitung penerimaan dan biaya yang dikeluarkan dengan satuan produksi dan satuan harga yang berlaku sebagaimana pada Tabel 4.

Tabel 4. Nilai Pendapatan Usahatani Setiap $100 \mathrm{Kg}$ Biji Kakao Asalan Hasil Nonfermentasi Di Wilayah Penelitian

\begin{tabular}{clll}
\hline No & \multicolumn{1}{c}{$\begin{array}{c}\text { Variabel } \\
\text { Pendapatan }\end{array}$} & $\begin{array}{l}\text { Volume } \\
\text { Satuan } \\
(\mathrm{Rp} / \mathrm{kg})\end{array}$ & $\begin{array}{c}\text { Total Nilai } \\
(\mathrm{Rp})\end{array}$ \\
\hline 1 & $\begin{array}{l}\text { Penerimaan biji } \\
\text { kakao asalan }\end{array}$ & 100 & $1.100 .000,00 .-$ \\
2 & Biaya- biaya & 100 & $700.000,00 .-$ \\
3 & Harga biji kakao/kg & 11.000. & $11.000,00 .-$ \\
\hline & Nilai Pendapatan & & $\mathbf{4 0 0 . 0 0 0 , 0 0 . -}$ \\
& $(1-2)$ & & \\
\hline
\end{tabular}

Pada Tabel 4, menunjukkan bahwa nilai pendapatan usahatani kakao dengan produk asalan (nonfermentasi) biji kakao adalah sejumlah Rp 400.000,00.- per setiap $100 \mathrm{~kg}$ biji kakao fermentasi. Hal tersebut berlaku pada tingkat harga jual biji kakao standar asalan (non fermentasi) sebesar Rp 11.000,per $\mathrm{kg}$, dan standar harga biji kakao basah sebesar Rp 7.000,- per kg di tingkat pedagang pengumpul kakao.

\section{c. Analisis Nilai Perbedaan Pendapatan Usahatani Kakao}

Berdasarkan pendapatan responden yang menerapkan teknik fermentasi lebih tinggi dari pendapatan responden yang tidak menerapkan teknik fermentasi. Untuk membuktikan secara statistik apakah perbedaan yang diperoleh ini nyata maka dilakukan analisis perbedaan mengenai pendapatan dengan uji beda nyata atau uji $\mathrm{t}$ sebagai berikut :

$\mathrm{t}_{\text {hitung }}=\frac{19.916 .083-14.870 .314}{\sqrt{\frac{7.607 .608^{2}}{30}+\frac{8.396 .009^{2}}{150}}}$ 


$$
\begin{aligned}
& =\frac{19.916 .083-14.870 .314}{\sqrt{1.929 .189 .982 .722+1.481 .316 .337 .825}} \\
& =\frac{19.916 .083-14.870 .314}{\sqrt{3.311 .405 .220 .547}} \\
& =\frac{5.045 .769}{1.819 .727} \\
& =2,77
\end{aligned}
$$

Taraf kepercayaan $95 \%: \mathrm{t}_{\text {tabel }}=1,96$ $(n=180)$.

Analisis perbedaan pendapatan menunjukkan bahwa $t_{\text {hitung(2,77) }}>t_{\text {tabel(1,96) }}$ pada taraf kepercayaan 95\% (Derajat Alfa $=0,05$ ), itu berarti terdapat perbedaan yang nyata antara pendapatan petani yang menerapkan teknik fermentasi dengan yang tidak menerapkan teknik fermentasi. Secara matematis perbedaan pendapatan hasil usahatani kakao bagi petani yang menerapkan agroindustri kakao dalam bentuk teknologi fermentasi biji kakao, memperoleh nilai tambah Rp 3.324.000,00.- $\quad(2,77 \quad$ x $\quad R p$ 1.600 .000 - Rp 400.000)/unit produksi (100 $\mathrm{kg}$ biji kakao fermentasi). Jika rata-rata produksi usahatani kakao rakyat $700 \mathrm{~kg} / \mathrm{ha}$, maka perolehan nilai tambah pendapatan petani kakao dapat dihitung sebesar (700/100 x Rp 3.324.000,00.- = Rp 23.268.000,00./ha/Tahun) atau rata-rata tambahan nilai pendapatan petani kakao sebesar Rp 1.939.000,00.- per bulan.

\section{KESIMPULAN}

1. Inovasi agroindustri untuk meningkatkan mutu kakao dilakukan petani kakao melalui proses fermentasi biji kakao, memberikan nilai pendapatan usahatani kakao rakyat rata-rata sebesar Rp.23.268.000,00.-/ha/Tahun, dibanding tanpa fermentasi atau biji kakao asalan dalam masyarakat perkebunan kakao di Kabupaten Konawe.

2. Perbedaan Pendapatan petani kakao yang menerapkan teknik fermentasi kakao dengan petani kakao yang tidak menerapkan fermentasi kakao "berbeda nyata" dengan stastik uji t hitung $(2,77)$ lebih besar dari t tabel $(1,96)$ pada taraf alpa $(\alpha: 0,05)$. Artinya ada perbedaan perolehan nilai pendapatan rata-rata sebesar $\quad \operatorname{Rp~1.200.000,00.-~per~unit~}$ produksi kakao.

3. Manfaat sosial-ekonomi dari Inovasi teknologi agroindustri kakao bagi masyarakat perkebunan adalah (a) Meningkatkan kualitas biji kakao, (b) Memasyarakatkan budaya mutu pada produksi perkebunan kakao rakyat, dan (c) Meningkat pendapatan petani kakao (nilai tambah) sebesar 52,17 persen sesuai harga jual kakao yang berlaku di pasaran konsumen.

\section{DAFTAR PUSTAKA}

BPS Provinsi Sultra, 2010. Sulawesi Tenggara Dalam Angka BPS Sultra. Kendari.

http://www.deptan.go.id/pedum2018/.../2.2\%

29pedoman-UFBK.pdf. Diakses 13 April 2018.

http://ditjenbun.deptan.go.id/bbp2tpsur/teknol ogi-fermentasi-untuk-meningkatkan-

kualitas-biji-kakao-indonesia. Diakses 13 April 2018.

https://www.tribunnews.com Diakses 2 Agustus 2018.

http://teknologi.kompasiana.com/terapan/201 1. Diakses 27 Mei 2018.

http://repository.usu.ac.id/bitstream/12345678 9/19470/.../chapter\%2018.pdf. Diakses 14 April 2018.

http://repository.usu.ac.id/bitstream/12345678 9/24809/chapterII.pdf. Diakses 14 April 2018.

Mangunwidjaya D, dan I Sailah, 2009. Pengantar Teknologi Pertanian. Jakarta: Penebar Swadaya.

Pusat Penelitian Kopi dan Kakao Indonesia. 2004. Panduan Lengkap Budi Daya Kakao. Jakarta: AgroMedia Pustaka. 
Saragih, B. 2011. Suara Dari Bogor: Membangun Sistem Agribisnis. Bogor: Sucofindo.

Soekartawi. 1990. Teori Ekonomi Produksi. Jakarta: Rajawali.

Sri Mulato, Sukrisno Widyotmo, Misnawi, Edy Suharyanto. 2010. Petunjuk Teknis Pengolahan Produk Primer dan Sekunder Kakao. Jember: Pusat Penelitian Kopi dan Kakao Indonesia. 